\title{
Focally Amplified Long Non-Coding RNA in Epithelial Cancer
}

National Cancer Institute

\section{Source}

National Cancer Institute. Focally Amplified Long Non-Coding RNA in Epithelial Cancer. NCI Thesaurus. Code C119657.

Focally amplified long non-coding RNA in epithelial cancer (566 bp) is encoded by the human FALEC gene. This non-coding RNA may be involved in oncogenesis. 